\title{
lodine deficiency, thyroid function and hearing deficit: a review
}

\author{
Alida Melse-Boonstra ${ }^{1 *}$ and Ian Mackenzie ${ }^{2}$ \\ ${ }^{1}$ Division of Human Nutrition, Wageningen University, Wageningen, The Netherlands \\ ${ }^{2}$ World Health Organization Collaborating Centre for Prevention of Deafness, Child and Reproductive Health, \\ Liverpool School of Tropical Medicine, Liverpool, UK
}

\begin{abstract}
Iodine deficiency affects an estimated 241 million school-aged children in the world. Little is known about iodine deficiency in relation to auditory function, except for the fact that deaf-mutism is one of the features of cretinism. In the present review, we documented the scientific knowledge on the role of iodine and hypothyroidism in the auditory system. We found that ear development and hearing function depend on thyroid hormones. Multiple pathways are involved in this, including both inner ear morphology as well as neurological processes. Conductive as well as sensorineural hearing loss is found in studies with animals that were rendered hypothyroidic. In humans, auditory impairment is reported frequently in relation to hypothyroidism, ranging from mild disturbances to severe handicap. Auditory impairment has been related more explicitly to congenital hypothyroidism than to acquired hypothyroidism. The critical period for thyroid function-related hearing maturation is the first and second trimesters of pregnancy. Although only a limited number of studies have directly investigated the relationship between iodine deficiency and auditory function, most studies point toward an association. However, evidence from good randomised controlled trials is lacking. Inclusion of auditory outcomes in iodine supplementation studies is therefore to be recommended, especially for trials in pregnancy. Hearing deficit is an invisible abnormality, but has major consequences for educational and social skills if not detected. In view of this, auditory impairment should be mapped in iodine-deficient areas in order to realistically estimate the magnitude of the problem.
\end{abstract}

Key words: Iodine deficiency: Thyroid function: Hearing deficit: School-aged children

\section{Introduction}

Iodine deficiency is still a significant public health problem in many countries throughout the world. It is estimated that in total 241 million school-aged children have some degree of iodine deficiency ${ }^{(1,2)}$, which forms a major threat to their developmental potential. It has been known for a few decades that an adequate iodine supply is particularly important during early life development ${ }^{(3-5)}$. Iodine deficiency, even when only mild to moderate, has repeatedly been found to be related to delayed or diminished cognitive development in children ${ }^{(6,7)}$. It has also been shown that the cognitive deficits related to mild-tomoderate iodine deficiency can still be reversed with iodine supplementation in children at school age ${ }^{(8-10)}$.

Impaired hearing function at an early age may well be linked to cognitive function and learning abilities in later life $^{(11)}$. A possible association between iodine deficiency and hearing function has not received much attention up until now, despite the fact that deaf-mutism is a common characteristic of severe iodine deficiency in addition to mental retardation ${ }^{(12,13)}$. The fact that the auditory system is related to thyroid dysfunction was recognised over 100 years ago ${ }^{(14)}$. Increased prevalence of all forms of congenital deafness has been reported from areas that were renowned for a high prevalence of endemic goitre, such as the Alps, Himalayas and Andes ${ }^{(15)}$. An association between iodine intake and auditory function has been suggested by several authors ${ }^{(16-19)}$. Early studies have mostly focused on severe iodine deficiency in relation to deafness and deaf-mutism ${ }^{(20,21)}$. However, the effect of milder forms of iodine deficiency in the physiopathological mechanisms of hearing impairment is largely unknown.

With the present review we aim to document and critically review the scientific evidence for an association between mild-to-moderate iodine deficiency and hearing function. Since hypothyroidism is an important consequence of iodine deficiency and is the major mechanism of the iodine deficiency disorders, the role of the thyroid in the auditory system is included in this review.

Abbreviations: ABR, auditory brainstem response; Tg, thyroglobulin; TR, thyroid hormone receptor; TSH, thyroid-stimulating hormone; T3, triiodothyronine; T4, thyroxine; UI, urinary iodine concentration. 


\section{lodine and thyroid metabolism in a nutshell}

Iodine is an essential component of the thyroid hormones triiodothyronine (T3) and thyroxine (T4). Iodine is taken up in the thyroid through the $\mathrm{Na}$ /iodide symporter. The thyroid of a healthy adult contains about $12-15 \mathrm{mg}$ iodine, whereas in iodine deficiency this can drop to $20 \mu \mathrm{g}^{(22)}$. Iodine is oxidised by the enzymes thyroperoxidase and hydrogen peroxidase and then organified to tyrosyl residues in thyroglobulin (Tg). The hormone precursors iodotyrosine and di-iodotyrosine that are produced then couple to form $\mathrm{T} 4$ or $\mathrm{T} 3$, still bound to $\mathrm{Tg}$. After Tg enters the thyrocyte by endocytosis, T4 and T3 are released into the circulation. Iodine uptake is regulated by thyroid-stimulating hormone (TSH), which is secreted at the pituitary. When iodine intake is low, increased TSH production stimulates expansion of the thyroid, resulting in goitre. Thyroid hormone receptors (TR), occurring as the two isoforms TR $\alpha$ and TR $\beta$, regulate thyroid hormone metabolism at the transcriptional level. TR genes encode nuclear receptors that can bind $\mathrm{T} 3$, and transcription can be either activated or deactivated by $\mathrm{TR}^{(23)}$. Both $\mathrm{TR} \alpha$ and TR $\beta$ are expressed in the cochlea ${ }^{(24)}$, and both play a distinct role in auditory development ${ }^{(23,25)}$.

\section{The auditory system}

The anatomical and structural parts of the auditory system develop very early in pregnancy; the cochleae in the middle ear are largely ready by 15 weeks of gestational age and the auditory system becomes connected to the brainstem and temporal lobe of the cortex between 25 and 30 weeks of gestational age ${ }^{(26)}$. The cochlea and the auditory cortex are most important in the developmental processes. Abnormalities in the hair cells of the organ of Corti result in sensorineural hearing loss. Conductive hearing loss is caused by obstructions in conducting sound waves; this can be anywhere along the route through the outer ear, tympanic membrane (eardrum) or middle ear (ossicles), for instance caused by the presence of ear wax or ear infections.

For the assessment of hearing loss, pure tone audiometry is the most commonly used method. It measures ear specific frequency thresholds and can distinguish between air and bone conductive hearing loss, the latter indicating a sensorineural cause. Since pure tone audiometry requires the cooperation of the individual assessed, it can only be used on adults and children that are old enough to understand the procedure and to respond. It requires careful calibration of the test environment and equipment. Over recent years, methods that measure hearing loss more objectively have been developed and are now widely used. Otoacoustic emission, which is a sound wave produced by the inner ear, can be measured non-invasively even in newborns. It is now used widely as a screening method for hearing loss in early life. Auditory brainstem response (ABR) is another method used for screening and diagnostic testing of hearing that measures electric potentials in response to an auditory stimulus via electrodes placed on the head. Both methods are well tried and reliable. For otoacoustic emission, quietness is necessary and ABR testing takes time, but both tests are very accurate in establishing hearing thresholds. Event-related potentials, specifically the P300 wave, can be used to assess auditory information processing in the central nervous system and are also a reliable method for quantitative evaluation of auditory impairment.

\section{Genetic factors, thyroid metabolism and auditory function}

Various genetic disorders indicate that the auditory system is linked to thyroid metabolism. The most well known is Pendred's syndrome, an autosomal thyroid disorder that leads to goitre and sensorineural hearing loss caused by genetic factors ${ }^{(27-29)}$. Recent studies revealed that mutations in the solute carrier SLC26A4 gene, which encodes for the protein pendrin, are responsible for Pendred's syndrome ${ }^{(30)}$. An enlarged vestibular aqueduct has also been attributed to genetic mutations in the same gene ${ }^{(31,32)}$. Pendrin is an iodine transporter that is located on the apical cells of thyroid follicular cells, but also in the inner ear and the kidney ${ }^{(33)}$. The functional change of the SLC26A4 gene product has been suggested to result in abolished apical iodide efflux and organification $^{(34)}$, leading to a disturbance in thyroid hormone synthesis. However, the organification defect is only mild and only seems to result in hypothyroidism under iodine-deficient conditions ${ }^{(35)}$. Therefore, it remains uncertain whether the sensorineural hearing loss associated with Pendred's syndrome is solely caused by hypothyroidism ${ }^{(23)}$.

Another syndrome, characterised by resistance to thyroid hormone and also referred to as Refetoff syndrome, results in a high amount of circulating thyroid hormones and high urinary iodine excretion, due to the inability to take up hormones in target tissues. Deafness and hearing loss are among the many symptoms that have been reported in patients with Refetoff syndrome ${ }^{(36-38)}$. Mutations in TR $\beta$ have been shown to be related to thyroid hormone resistance $^{(39)}$, and TR $\beta$ has been found to be essential in auditory development ${ }^{(25)}$. The thyroid $\beta$ receptors localised in the cochlea are involved in auditory ontogenesis ${ }^{(40)}$. Animal studies have revealed that $\mathrm{TR} \alpha$ and $\mathrm{TR} \beta$ are not homogeneously distributed throughout the auditory system. Mice that are deficient in $\operatorname{TR} \beta\left(\operatorname{TR} \beta^{-/-}\right)$have impaired evoked auditory brainstem potentials ${ }^{(25)}$.

It has been found that the expression of mRNA of $5^{\prime}$-deiodinase type II, which is responsible for the conversion of $\mathrm{T} 4$ to the active $\mathrm{T} 3$ form, increases in the auditory pathways after induction of hypothyroidism in rats ${ }^{(41)}$ Later studies have revealed that the most important transcriptional factor for prestin, the motor protein of outer 
hair cells in the cochlea, is regulated by thyroid hormones $^{(42)}$ and by $\operatorname{TR}^{(43)}$. In addition, it has been shown that $K c n q 4$, a gene encoding an outer hair cell $\mathrm{K}$ channel protein, is regulated by $\mathrm{TR} \alpha 1^{(43)}$, and that thyroid hormone regulates the expression of genes related to outer hair cell function, such as Tectb ${ }^{(44)}$. The Duox 2 gene is responsible for the production of $\mathrm{H}_{2} \mathrm{O}_{2}$, which is an essential cofactor in the production of thyroid peroxidase needed for the incorporation of iodine into Tg. Mice with the Duox2 CV674G mutation have been shown to have dyshormonogenesis and 50-60 dB higher hearing thresholds in comparison with control mice ${ }^{(45)}$. These findings indicate that thyroid hormones and their receptors are most probably involved in the auditory system through multiple pathways.

\section{Congenital and acquired hypothyroidism, development} of the auditory system and hearing function

Both non-genetic congenital and acquired hypothyroidism have been suggested to be causal to hearing loss ${ }^{(46,47)}$. In this section, the empirical evidence for this causality derived from animal and human studies is described.

\section{Animal studies}

In early studies in rats and chickens, in utero induction of hypothyroidism was shown to induce a delay in maturity and a degeneration of the sensitive epithelium of the inner ear, a distortion of the tectorial membrane, and the presence of acidophilic precipitates in the ductus ${ }^{(48-53)}$. For example, Meyerhoff ${ }^{(50)}$ did a series of experiments in which guinea-pigs were experimentally kept hypothyroidic during gestation in various ways. He found all hypothyroid animals to have elevated auditory thresholds using quantitative brainstem response as a physiological measure of auditory function. Morphologically, hypothyroid adult rats and their offspring showed alterations in the bone structure of the bullae, cochlea, as well as of the middle ear ossicles. The middle ear function relates to sound conduction, and morphological alterations can lead to conductive hearing loss. Other identified alterations included tectorial membrane distortion, inner and outer hair cell distortion, large dark staining lipid deposits of Hensen's cells, debris and acidophilic precipitate in the cochlear duct, and enlarged intracellular spaces in the stria vascularis. In general, Meyerhoff ${ }^{(50)}$ found the audiological changes to be more severe in offspring than in the hypothyroid parent animals. Thyroid hormones and receptors were further shown to play an essential role in hearing maturation by others ${ }^{(54-57)}$, and it was demonstrated later that spiking activity of inner hair cells is under the control of thyroid hormones ${ }^{(58)}$. In addition, thyroid hormones have been suggested not only to be necessary for the maturation of the cochlear organ but also of the central auditory areas ${ }^{(24,59)}$. It is also worthwhile mentioning that exposure to polychlorinated biphenyl during fetal development impairs auditory function in rats $^{(60)}$. Polychlorinated biphenyls are pollutants that share structural features with thyroid hormones and can interfere with the endocrine system ${ }^{(61-63)}$.

Dussault \& Ruel ${ }^{(64)}$ found that experimentally induced gestational hypothyroidism in rats led to permanent auditory impairment as measured by ABR in offspring at age 200 d. Similarly, Goldey et al. ${ }^{(65)}$ showed that gestational hypothyroidism in rats at various gradations led to diminished and delayed responses to noise stimuli in offspring, measured as startling response. Also, they found higher auditory thresholds with increasing severity of hypothyroidism which persisted even when rats reached adulthood. When hypothyroidism was induced postnatally beyond day 10, auditory impairment was no longer permanent as measured at the age of $120 \mathrm{~d}$. Also, when T4 treatment was given before day 10, permanent abnormalities were prevented $^{(64)}$. In contrast, Ritter ${ }^{(51)}$ reports an experiment in which 21-d-old chicks were exposed to propylthiouracil or radioiodine $\left({ }^{131} \mathrm{I}\right)$. Only five out of 166 experimental animals had some degree of hearing loss ranging from 30 to $45 \mathrm{~dB}$ and all of these five animals had a middle ear infection that could explain the hearing loss ${ }^{(51)}$. It can also not be excluded that in these experiments findings were not due to hypothyroidism per se but to a secondary effect of the hypothyroidism-inducing agent (propylthiouracil) decreasing the conversion of $\mathrm{T} 4$ to $\mathrm{T} 3$.

In another experiment with rats, hypothyroidism was induced at various intervals during pregnancy and in the postnatal period, and distortion product otoacoustic emissions and auditory evoked brainstem responses were measured at regular timings ${ }^{(66)}$. Results from this experiment showed that hypothyroidism from mid-pregnancy until the onset of hearing ability at postnatal day 12 led to elevated hearing thresholds (about $65 \mathrm{~dB}$ in offspring of hypothyroidic dams $v .25 \mathrm{~dB}$ in controls) and did not improve over time. Offspring of dams in which hypothyroidism was induced in early pregnancy (before the onset of the fetal thyroid gland) were not different from the offspring of dams with later induced hypothyroidism in terms of morphology of the cochlea and the organ of Corti, nor of hearing thresholds. This suggests that hearing impairment is not due to maternal thyroid hormone concentrations. Prolonged hypothyroidism up until postnatal day 28, however, resulted in morphological changes of the cochlea ${ }^{(67)}$. Translation of these findings to the human situation would suggest that shortage of thyroid hormones due to iodine deficiency between 10 and 29 weeks of gestational age forms a critical time window for congenital hearing deficiencies ${ }^{(66)}$.

\section{Human studies}

Various investigators have reported an association between thyroid hormone concentrations and hearing function in 
humans. In 1956, Hilger ${ }^{(68)}$ described various case studies in which hypothyroidism appeared to be related to hearing loss, which could be restored with T4 therapy. Bhatia et $a l^{(47)}$ found that of seventy-two hypothyroid patients, $43 \%$ had mild hearing loss as assessed by pure tone audiometry ${ }^{(47)}$. Malik et al. ${ }^{(69)}$ also report a higher degree of hearing loss in forty-five hypothyroid patients (age range 10-57 years) with decreasing concentrations of $\mathrm{T} 3$ and T4, or increasing concentrations of TSH. Based on a variety of auditory tests that their patients underwent, they conclude that hypothyroidism affects hearing function in various ways and may result in conductive as well as in sensorineural or mixed hearing impairment. Treatment with $\mathrm{T} 44$ resulted in improved hearing thresholds. In another study, four out of ten patients with mild congenital hypothyroidism had moderate or severe bilateral sensorineural hearing loss. The four patients with hearing loss were significantly older (22 v. 10 years) and had started later with levothyroxine treatment (17 v. 2.5 years) in comparison with the patients without hearing loss ${ }^{(57)}$. Thornton \& Jarvis ${ }^{(70)}$ reported a higher frequency of hearing loss in a group of twenty-one hypothyroid individuals as compared with thirty-one controls. They speculate that the hearing loss may be caused by lower body temperature of the hypothyroid patients. However, they do not provide details on the body temperature measurements, nor did they control for thyroid hormone concentrations. Using eventrelated potentials, Ozisik \& Arman ${ }^{(71)}$ found that the P300 latency was increased in twelve hypothyroid patients, indicating sensorineural hearing loss, as compared with twenty-seven controls.

Of forty-six patients with congenital hypothyroidism, half of the patients had loss of hearing function, of which five had severe or profound hearing $\operatorname{loss}^{(72)}$. In a group of forty-five children with congenital hypothyroidism, nine were diagnosed with sensorineural hearing loss, and four of them were reported as having speech and language problems. After receiving a hearing aid, children were reported to improve in speech, language skills and behaviour $^{(73)}$. Debruyne et $a l^{(74)}$ reported that of forty-five paediatric patients with congenital hypothyroidism, $20 \%$ had some degree of deafness. Similarly, Rovet et al. ${ }^{(75)}$ reported that among a group of seventy-five children with congenital hypothyroidism, 20\% had persisting mild hearing impairment (either conductive, sensorineural, or both), whereas the prevalence was only $0 \cdot 24 \%$ in the general paediatric population. Moreover, these children scored lower on various language tests until late in childhood, indicating delayed speech acquisition and difficulties in comprehension. In children with hearing impairment, L-thyroxine treatment had started somewhat later than in children with normal hearing function (day $22 v$. day 13), indicating a critical window of thyroid hormonedependent auditory development in the third week of life.

Hébert et al. ${ }^{(76)}$ compared auditory function of thirty-six children with congenital hypothyroidism, who were treated with T4 upon neonatal diagnosis, with twentyfour control children using ABR. They found significant auditory abnormalities in the treated hypothyroid children. François et al. ${ }^{(17)}$ did not find a difference in hearing thresholds measured by impedance audiometry between forty-two infants and children with congenital hypothyroidism on L-thyroxine treatment when compared with matched controls. Radetti et al. ${ }^{(77)}$ compared the hearing function of nine children born to mothers who were treated with L-thyroxine for subclinical hypothyroidism early in pregnancy with that of nine control children at 9 months of age using ABR. They did not find any differences in hearing function between the two groups. Su et al. ${ }^{(78)}$ found that hearing dysplasia was more prevalent among infants born to hyperthyroid mothers $(5 \cdot 6 \% ; n$ 18) as compared with normothyroid mothers $(0.5 \% ; n$ 845) using ABR at $42 \mathrm{~d}$ and at 2 and 3 months of age. In the same study, no cases born to nine clinical or forty-one subclinical hypothyroid mothers were found.

\section{lodine deficiency and hearing function in children}

Since thyroid hormones play such a critical role in various parts of the auditory system, it can be hypothesised that mild-to-moderate iodine deficiency may affect hearing function as well. In 1945, Wespi ${ }^{(79)}$ described how the incidence of deaf-mutism in various Swiss cantons declined rapidly after the introduction of iodine prophylaxis in $1923^{(15)}$. Kochupillai et $a l^{\left({ }^{(8)}\right.}$ found sensorineural hearing loss in eighteen out of ninety-three schoolchildren from a severely iodine-deficient village in Deoria district, India. Todd $e t a l{ }^{(81)}$ report data on auditory function in mildto-moderate iodine-deficient schoolchildren $(n$ 43) living in Zimbabwe, not showing impairment of hearing thresholds. Valeix et $a l^{(82)}$ report data from French preschool children ( $n$ 1222) aged 10 months, 2 years and 4 years. They found that hearing loss at $4000 \mathrm{~Hz}$ and at speech frequencies were more severe among children with urinary iodine concentration (UI) $<100 \mu \mathrm{g} / \mathrm{l}$ as compared with those with UI $>100 \mu \mathrm{g} / \mathrm{l}$. The correlation between hearing thresholds and UI was $r 0.10(P<0.02)$ at $4000 \mathrm{~Hz}$ and $r 0.03(P<0.25)$ at speech frequencies. In a cross-sectional study conducted among schoolchildren in Iran ( $n$ 1045), Azizi et al. ${ }^{(83)}$ showed that the prevalence of abnormal hearing function was 44 and $15 \%$, respectively, in two villages where children had low UI, whereas the prevalence was $2 \%$ in a third village where children had close to normal UI. The mean hearing threshold was significantly increased in the village with the lowest UI $(15.4 \quad(\operatorname{sD} 6.0) \quad v .13 .2 \quad(\operatorname{sD~} 3.2) \mathrm{dB} \quad(P<0.005)$ and 12.4 $(\mathrm{SD} 2 \cdot 1) \mathrm{dB}(P<0 \cdot 001)$, respectively). A study in 381 Chinese children showed that iodine contents in hairs of children with perceptive nerve deafness were much lower than those of healthy children $(P<0 \cdot 01)^{(84)}$. A study among 150 Spanish schoolchildren showed an inverse relationship between the auditory thresholds at all frequen- 
cies and UI in those with palpable goitre. Moreover, those with $\mathrm{Tg}$ values $>10 \mathrm{ng} / \mathrm{ml}$, a marker for possible iodine insufficiency, had higher auditory thresholds at all frequencies, and children with a thyroid size $>95$ th percentile had an OR of $3.86(95 \%$ CI $2 \cdot 59,5 \cdot 10)$ of having a threshold $>20 \mathrm{~dB}^{(85)}$.

Although an association between iodine deficiency and impaired hearing function has been found in most of the studies reviewed above, this does not provide sufficient evidence for causality. Only a few studies have directly investigated the effect of iodine supplementation on hearing function in humans. In 1985, Wang \& Yang ${ }^{(86,87)}$ assessed hearing thresholds in a non-randomised controlled study among 120 schoolchildren living in either an iodine-deficient village or a non-deficient village in China. They found that 3 years after the introduction of iodised salt in the deficient village, hearing thresholds came down from $17 \cdot 4 \mathrm{~dB}$ to $8 \cdot 2 \% \mathrm{~dB}$, which was almost similar to thresholds in the control village $(7.5 \% \mathrm{~dB})$. Azizi et al., following up on their earlier study in which they found impaired hearing function in children from an iodine-deficient Iranian village ${ }^{(83)}$, found that after iodised salt had been introduced in the area, the distribution of hearing thresholds made a clear shift towards lower values ${ }^{(88)}$. Van den Briel et al. ${ }^{(89)}$ reported auditory data from a randomised placebo-controlled trial ( $n$ 197) conducted in Benin, in which half of the children received an oral dose of oil with $540 \mathrm{mg}$ iodine and the other half received placebo. After 11 months, auditory measurements were taken, which correlated with $\mathrm{Tg}$ concentrations at that time point $(r 0 \cdot 15 ; P<0.05)$, but not with T4, TSH or UI. No comparison was made between treatment groups since iodised salt was introduced in the study area while the study was ongoing, thereby also exposing the placebo group to iodine.

\section{Conclusion}

In summary, the scientific literature indicates that ear development and hearing function depend on thyroid hormones through different pathways, including both inner ear morphology as well as neurological processes. Induced hypothyroidism in animals causes various auditory alterations, relating to both conductive as well as sensorineural hearing loss. In humans, auditory impairment is reported frequently in relation to hypothyroidism, ranging from mild disturbances to severe handicap. Congenital hypothyroidism has been related more explicitly to auditory impairment than acquired hypothyroidism. During critical developmental stages, shortage of T3 might fail to adequately stimulate hormone-receptor interaction in the corresponding auditory structures ${ }^{(24)}$. In humans, the critical period for hearing maturation corresponds approximately to an interval ranging from the early embryonal period to the first year of postnatal life ${ }^{(26)}$. Although the fetal thyroid is formed by 10-12 weeks of gestation, the fetus remains dependent on maternal thyroid hormones through transplacental passage until the fetal thyroid starts to produce thyroid hormones at 16-20 weeks of gestation $^{(64)}$. Hypothyroidism occurring during this critical time window can lead to irreversible hearing impairment $^{(66)}$. However, when T4 therapy is begun early enough in life $(<1$ year), it might still successfully reverse hearing loss ${ }^{(57)}$.

As described in the present review, only a few studies have evaluated associations between mild-to-moderate iodine deficiency and auditory function. The limited evidence does suggest that iodine deficiency is related to hearing loss, and that supplementation of iodine-deficient individuals may improve hearing thresholds. However, no solid randomised controlled trial was encountered in the literature to support this. Moreover, the effect of iodine deficiency on hearing function is likely to be largest during pregnancy. It would therefore be worthwhile to include auditory function as an outcome in studies investigating effects of iodine supplementation, especially during pregnancy.

Hearing deficit is a poorly reported disability as there is no physical abnormality ${ }^{(90)}$. It is well recognised that the earlier hearing deficit is identified and managed, the more improved will be a child's educational and social skills $^{(11)}$. In areas of mild-to-moderate iodine deficiency, such as large parts of Europe, Asia and sub-Saharan Africa $^{(1)}$, auditory impairment due to hypothyroidism might exist. From a public health perspective, it would be helpful if the prevalence and severity of auditory impairment in relation to the degree of iodine deficiency were mapped in order to obtain a better view on the magnitude of the problem.

\section{Acknowledgements}

We would like to thank Ms Agnes Omusundi, who helped with the retrieval of some of the literature used in this paper. We also thank Professor Dr Michael Zimmermann for proofreading the final draft.

This research received no specific grant from any funding agency in the public, commercial or not-for-profit sectors.

A. M.-B. drafted the first version of the manuscript; I. M. contributed significantly to follow-up versions.

The authors have no conflicts of interest.

\section{References}

1. Andersson M, Karumbunathan V \& Zimmermann MB (2012) Global iodine status in 2011 and trends over the past decade. J Nutr 142, 744-750.

2. Pearce EN, Andersson M \& Zimmermann MB (2013) Global iodine nutrition - where do we stand in 2013? Thyroid 23, 523-528.

3. DeLange F (1994) The disorders induced by iodine deficiency. Thyroid 4, 107-128. 
4. Zimmermann MB (2007) The adverse effects of mild-tomoderate iodine deficiency during pregnancy and childhood: a review. Thyroid 17, 829-835.

5. Walker SP, Wachs TD, Gardner JM, et al. (2007) Child development: risk factors for adverse outcomes in developing countries. Lancet 369, 145-157.

6. Bleichrodt N, Drenth P \& Querido A (1980) Effects of iodine deficiency on mental and psychomotor abilities. Am J Phys Anthropol 53, 55-67.

7. Qian M, Wang D, Watkins WE, et al. (2005) The effects of iodine on intelligence in children; a metaanalysis of studies conducted in China. Asia Pac J Clin Nutr 14, 32-42.

8. Zimmermann MB, Connolly K, Bozo M, et al. (2006) Iodine supplementation improves cognition in iodine-deficient schoolchildren in Albania: a randomized, controlled, double-blind study. Am J Clin Nutr 83, 108-114.

9. Gordon RC, Rose MC, Skeaff SA, et al. (2009) Iodine supplementation improves cognition in mildly iodine-deficient children. Am J Clin Nutr 90, 1264-1271.

10. Melse-Boonstra A \& Jaiswal N (2010) Iodine deficiency in pregnancy, infancy and childhood and its consequences for brain development. Best Pract Res Clin Endocrinol Metab 24, 29-38.

11. Yoshinago-Itano C \& Apuzzo ML (1998) Identification of hearing loss after 18 months is not early enough. Am Ann Deaf 143, 380-387.

12. DeLong GR (1993) Effects of nutrition on brain development in humans. Am J Clin Nutr 57, 286S-290S.

13. Chen ZP \& Hetzel BS (2010) Cretinism revisted. Best Pract Res Clin Endocrinol Metab 24, 39-50.

14. Bircher H (1883) Der endemische Kropf und seine Beziehungen zur Taubstummbeit und zum Kretinismus (Endemic Goitre in Relation to Deaf-mutism and Cretinism). Basel: Benno Schwabe.

15. Trotter WR (1960) The association of deafness with thyroid dysfunction. Br Med Bull 16, 92-98.

16. Malgorzata W, Flipod L, Sergious G, et al. (2002) Hearing loss in congenital hypothalamic hypothyroidism: a wide therapeutic window. Hearing Res 172, 87-91.

17. François M, Bonfils P, Leger J, et al. (1994) The role of congenital hypothyroidism in hearing loss in children. J Pediatr 124, 444-446.

18. Goslings B, Hoedijonor H, Soepardjo H, et al. (1975) Studies on hearing loss in a community with endemic cretinism in Central Java, Indonesia. Acta Endocrinol (Copenh) $\mathbf{7 8 ,}$ $705-713$.

19. Maberly GF, Haxton DP \& Van der Haar F (2003) Iodine deficiency: consequences and progress toward elimination. Food Nutr Bull 24, S91-S98.

20. McCarrison R (1908) Observation on endemic cretinism in the Chitral and Gilgit Valleys. Lancet ii, 1275-1280.

21. Boyages SC, Halpern JP, Marbley JF, et al. (1988) A comparative study of neurological and myxedematous endemic cretinism in Western China. J Clin Endocrinol Metab 67, 1262-1271.

22. Zimmermann MB, Jooste PL \& Chandrakant SP (2008) Iodine deficiency disorders. Lancet 372, 1251-1262.

23. Forrest D (1996) Deafness and goiter: molecular genetic considerations. J Clin Endocrinol Metab 81, 2764-2767.

24. Bradley DJ, Towle HC \& Young WS III (1994) Alpha and beta thyroid hormone receptor (TR) gene expression during auditory neurogeneis: evidence for TR isoform-specific transcriptional regulation in vivo. Proc Natl Acad Sci U S A 91 , 439-443.

25. Forrest D, Erway LC, Ng L, et al. (1996) Thyroid hormone receptor $\mathrm{B}$ is essential for development of auditory function. Nature Genet 13, 354-357.
26. Graven SN \& Browne JV (2008) Auditory development in the fetus and infant. Newborn Infant Nurs Rev 8, 187-193.

27. Coakley JC, Keir EH \& Connelly JF (1992) The association between thyroid dyshormonogenesis and deafness (Pendred syndrome): experience of the Victorian neonatal thyroid screening program. I Paediatr Child Health 28, 398-401.

28. Coyle B, Coffey R, Armour JAL, et al. (1996) Pendred syndrome (goitre and sensorineural hearing loss) maps to chromosome 7 in the region containing the nonsyndromic deafness gene DFNB4. Nature Genet 12, 421-423.

29. Sheffield VC, Kraiem Z, Beck JC, et al. (1996) Pendred syndrome maps to chromosome 7q21-34 and is caused by an intrinsic defect in thyroid iodine organification. Nature Genet 12, 424-426.

30. Dror AA, Brownstein Z \& Avraham KB (2011) Integration of human and mouse genetics reveals pendrin function in hearing and deafness. Cell Physiol Biochem 28, 535-544.

31. Bogazzi F, Russo D, Raggi F, et al. (2004) Mutations in the SLC26A4 (pendrin) gene in patients with sensorineural hearing loss and enlarged vestibular aqueduct. J Endocrinol Invest 27, 430-435.

32. Madeo AC, Manichaikul A, Reynolds JC, et al. (2009) Evaluation of the thyroid in patients with hearing loss and enlarged vestibular aqueducts. Arch Otolaryngol Head Neck Surg 135, 670-676.

33. Dossena S, Nofziger C, Lang F, et al. (2011) The ESF meeting on the proteomics, epigenetics and pharmacogenetics of pendrin. Cell Physiol Biochem 28, 377-384.

34. Scott DA, Wang R, Kreman TM, et al. (2000) Functional differences of the PDS gene product are associated with phenotypic variation in patients with Pendred syndrome and non-syndromic hearing loss (DFNB4). Hum Mol Genet 9, 1709-1715.

35. Bizhanova A \& Kopp P (2011) Controversies concerning the role of pendrin as an apical iodide transporter in thyroid follicular cells. Cell Physiol Biochem 28, 485-490.

36. Refetoff S, De Wind LT \& De Groot LJ (1967) Familial syndrome combining deaf-mutism, stuppled epiphyses, goiter and abnormally high PBI: possible target organ refractoriness to thyroid hormone. Clin Endocrinol Metab 27, 279-294.

37. Brucker-Davis F, Skarulis MC, Grace MB, et al. (1995) Genetic and clinical features of 42 kindreds with resistance to thyroid hormone. The National Institutes of Health Prospective Study. Ann Intern Med 123, 572-583.

38. Brucker-Davis F, Skarulis MC, Pikus A, et al. (1996) Prevalence and mechanisms of hearing loss in patients with resistance to thyroid hormone (RTH). J Clin Endocrinol Metab 81, $2768-2772$.

39. Refetoff S, Weiss RE \& Usala SJ (1993) The syndromes of resistance to thyroid hormone. Endocr Rev 14, 348-399.

40. Corey DP (1994) Transcription factors in inner ear development. Proc Natl Acad Sci U S A 91, 433-436.

41. Guadano-Ferraz A, Escamez MJ, Rausell E, et al. (1999) Expression of type 2 iodothyronine deiodinase in hypothyroid rat brain indicates an important role of thyroid hormone in the development of specific primary sensory systems. J Neurosci 19, 3430-3439.

42. Weber T, Zimmermann U, Winter H, et al. (2002) Thyroid hormone is a critical determinant for the regulation of the cochlear motor protein prestin. Proc Natl Acad Sci US A 99, 2901-2906.

43. Winter H, Braig C, Zimmermann U, et al. (2006) Thyroid hormone receptors TR $\alpha 1$ and TR $\beta$ differentially regulate gene expression of Kcnq4 and prestin during final differentiation of outer hair cells. J Cell Sci 119, 2975-2984. 
44. Knipper M, Richardson G, Mack A, et al. (2001) Thyroid hormone-deficient period prior to the onset of hearing is associated with reduced levels of $\beta$-tectorin protein in the tectorial membrane. Implications for hearing loss. $J$ Biol Chem 276, 39046-39052.

45. Johnson KR, Marden CC, Ward-Bailey P, et al. (2007) Congenital hypothyroidism, dwarfism, and hearing impairment caused by a missense mutation in the mouse dual oxidase 2 gene, Duox2. Mol Endocrinol 21, 1593-1602.

46. Anand VT, Mann SBS, Dash RJ, et al. (1989) Auditory investigations in hypothyroidism. Acta Otolaringol 108, 83-87.

47. Bhatia PL, Gupta OP, Agrawal MK, et al. (1977) Audiological and vestibular function test in hypothyroidism. Laryngoscope 87, 2082-2089.

48. Ritter FN \& Lawrence M (1960) Reversible hearing loss in human hypothyroidism and correlated changes in the chick inner ear. Trans Am Laryngol Rhinol Otol Soc 70, 393-407.

49. Deol MS (1973) An experimental approach to the understanding and treatment of hereditary syndromes with congenital deafness and hypothyroidism. J Med Genet 10, 235-242.

50. Meyerhoff WL (1979) Hypothyroidism and the ear: electrophysiological, morphological, and chemical considerations. Laryngoscope 89, Suppl. 19, 1-25.

51. Ritter FN (1967) The effect of hypothyroidism upon the ear, nose and throat. Laryngoscope 77, 1427-1479.

52. Uziel A, Gabrion J, Ohresser M, et al. (1981) Effects of hypothyroidism on the structural development of the organ of Corti in the rat. Acta Otolaryngol 92, 469-480.

53. Kohonen A, Jauhiain T, Liewenda K, et al. (1971) Deafness in experimental hypothyroidism and hyperthyroidism. Laryngoscope 81, 947-956.

54. Uziel A, Legrand C \& Rabie A (1982) Effects of hypothyroidism in cochlear abnormalities induced by congenital hypothyroidism in the rat. Morphol Stud Dev 29, 361-370.

55. Deol MS (1976) The role of thyroxine in the differentiation of the organ of Corti. Acta Otolaryngol 81, 429-435.

56. Van Middlesworth L \& Norris CH (1980) Audiogeneic seizures and cochlear damage in rats after prenatal antithyroid treatment. Endocrinology 106, 1686-1690.

57. Wasniewska M, De Luca F, Siclari S, et al. (2002) Hearing loss in congenital hypothalamic hypothyroidism: a wide therapeutic window. Hear Res 172, 87-91.

58. Brandt N, Kuhn S, Münkner S, et al. (2007) Thyroid hormone deficiency affects postnatal spiking activity and expression of $\mathrm{Ca}^{2+}$ and $\mathrm{K}^{+}$channels in rodent inner hair cells. $J$ Neurosci 27, 3174-3186.

59. Ruiz-Marcos A, Salas J, Sanchez-Toscano J, et al. (1983) Effect of neonatal and adult onset hypothyroidism on pyramidal cells in the rat auditory cortex. Brain Res 9, 205-213.

60. Goldey ES, Kehn LS, Lau C, et al. (1995) Developmental exposure to polychlorinated biphenyls (Aroclor 1254) reduces circulating thyroid hormone concentrations and causes hearing deficits in rats. Toxicol Appl Pharmacol 135, $77-88$.

61. Rickenbacher U, McKinney JD, Oatley SJ, et al. (1986) Structurally specific binding of halogenated biphenyls to thyroxine transport protein. J Med Chem 29, 641-648.

62. McKinney JD (1989) Multifunctional receptor model for dioxin and related compound toxic action: possible thyroid hormone-responsive effector-linked site. Environ Health Perspect 82, 323-336.

63. McKinney JD \& Waller CL (1994) Polychlorinated biphenyls as hormonally active structural analogues. Environ Health Perspect 102, 290-297.

64. Dussault JH \& Ruel J (1987) Thyroid hormones and brain development. Ann Rev Physiol 49, 321-334.
65. Goldey ES, Kehn LS, Rehnberg GL, et al. (1995) Effects of developmental hypothyroidism on auditory and motor function in the rat. Toxicol Appl Pharmacol 135, 67-76.

66. Knipper M, Zinn C, Maier H, et al. (2000) Thyroid hormone deficiency before the onset of hearing causes irreversible damage to peripheral and central audiotory systems. J Neurophysiol 83, 3101-3112.

67. Knipper M, Gestwa L, Ten Cate WJ, et al. (1999) Distinct thyroid hormone-dependent expression of TrkB and p75NGFR in nonneuronal cells during the critical TH-dependent period of the cochlea. $J$ Neurobiol 38, 338-356.

68. Hilger JA (1956) Otolaryngologic aspects of hypometabolism. Ann Otol Rhinol Laryngol 65, 395-413.

69. Malik V, Shukla GK \& Bhatia N (2002) Hearing profile in hypothyroidism. Indian J Otolaryngol Head Neck Surg $\mathbf{5 4}$, 285-290.

70. Thornton AR \& Jarvis SJ (2008) Auditory brainstem response findings in hypothyroid and hyperthyroid disease. Clin Neurophysiol 119, 786-790.

71. Ozisik HI \& Arman F (2008) Evaluation of auditory eventprovoked potentials in hyperthyroid and hypothyroid patients. Endocrinologist 18, 286-289.

72. Crifò S, Lazzari R, Salabè GB, et al. (1980) A retrospective study of audiological functions in a group of congenital hypothyroid patients. Int $J$ Pediatr Otorbinolaryngol $\mathbf{2}$, $347-355$.

73. Vanderschueren-Lodeweyckx, De Bruyne F, Dooms L, et al. (1983) Sensorineural hearing loss in sporadic congenital hypothyroidism. Arch Dis Child 58, 419-422.

74. Debruyne F, Vandeschuren-Lodeweyckx M \& Bastijns P (1983) Hearing in congenital hypothyroidism. Audiology 22, 404-409.

75. Rovet J, Walker W, Bliss B, et al. (1996) Long-term sequelae of hearing impairment in congenital hypothyroidism. $J$ Pediatr 128, 776-783.

76. Hébert R, Laureau E, Vanasse M, et al. (1986) Auditory brainstem response audiometry in congenitally hypothyroid children under early replacement therapy. Pediatr Res 20, 570-573.

77. Radetti G, Gentili L, Paganini C, et al. (2000) Psychomotor and audiologic assessment of infants born to mothers with subclinical thyroid dysfunction in early pregnancy. Minerva Pediatr 52, 691-698.

78. Su PY, Huang K, Hao JH, et al. (2011) Maternal thyroid function in the first twenty weeks of pregnancy and subsequent fetal and infant development: a prospective populationbased cohort study in China. J Clin Endocrinol Metab 96, 3234-3241.

79. Wespi HJ (1945) Abnahme der taubstummheit in der Schweiz als folge der kropfprophylaxe mit jodiertem kochsalz (Decrease in deaf-mutism in Switzerland as a result of goiter prophylaxis with iodised salt). Schweizerischen Medizinischen Wochenschrift 75, 625.

80. Kochupillai N, Pandav CS, Godbole MM, et al. (1986) Iodine deficiency and neonatal hypothyroidism. Bull WHO 64 , 547-551.

81. Todd CH, Sanders D \& Chimanyiwa T (1988) Hearing in primary-school children in an iodine-deficient population in Chinamhora, Zimbabwe. Trop Geograph Med 40, 223-225.

82. Valeix P, Preziosi P, Rossignol C, et al. (1994) Relationship between urinary iodine concentration and hearing capacity in children. Eur J Clin Nutr 48, 54-59.

83. Azizi F, Kalani H, Kimiagar M, et al. (1995) Physical neuromotor and intellectual impairment in non-cretinous school children with iodine deficiency. Int J Vitamin Nutr Res $\mathbf{6 5}$, 199-205. 
84. Gao H, Li J \& Wang E (1998) Iodine deficiency and perceptive nerve deafness. Lin Chuang Er Bi Yan Hou Ke Za Zhi 12, 228-230.

85. Soriguer F, Millon MC, Munoz R, et al. (2000) The auditory threshold in a school-age population is related to iodine intake and thyroid function. Thyroid 10, 991-999.

86. Wang YY \& Yang SH (1985) Occult impaired hearing among 'normal' school children in endemic goitre and cretinism areas due to iodine deficiency in Guizhou. Chin Med J 98 , 89-94.

87. Wang YY \& Yang SH (1985) Improvement in hearing among otherwise normal schoolchildren in iodine-deficient areas of
Guizhou, China, following use of iodised salt. Lancet ii, 518-520.

88. Azizi F, Mirmiram P, Hedayati M, et al. (2005) Effect of $10 \mathrm{yr}$ of the iodine supplementation on the hearing threshold of iodine deficient schoolchildren. J Endocrinol Invest 28, $595-598$

89. Van den Briel T, West CE, Hautvast JGAJ, et al. (2001) Mild iodine deficiency is associated with elevated hearing thresholds in children in Benin. Eur J Clin Nutr 55, $763-768$.

90. Mackenzie I \& Smith A (2009) Deafness - the neglected and hidden disability. Ann Trop Med Parasitol 103, 565-571. 